\section{High-protein rice in high-yielding background, cv. Naveen}

\section{Krishnendu Chattopadhyay ${ }^{1, *}$, Srigopal Sharma ${ }^{1}$, Torit Baran Bagchi ${ }^{1}$, Bimal Mohanty ${ }^{2}$, Sushree Sibanee Sardar ${ }^{1}$, Sutapa Sarkar ${ }^{1}$ and Onkar Nath Singh ${ }^{1}$}

${ }^{1}$ ICAR-National Rice Research Institute, Cuttack 753 006, India ${ }^{2}$ Central Inland Fisheries Research Institute, Barrackpore 700120 , India

While the developing world is approaching towards food security, nutritional aspects must be addressed properly to combat malnutrition. As the staple food of half of the world's population, rice is a major source of nutrition and needs to be nutritionally enriched with proteins, micronutrients, etc. With the objective of quantitative and qualitative improvement of grain protein content (GPC) in a popular high-yielding background, 'Naveen', we developed backcross population using high GPC (11\%-13\%) donor, ARC 10075. The range of $\mathrm{GPC}$ in $\mathrm{BC}_{3} \mathrm{~F}_{4}$ lines was $7.13 \%-13.6 \%$, estimated through calibrated NIR spectroscopy. Among the population lines, seven having phenotypic similarity with the recurrent parent, Naveen were identified based on high yield coupled with high protein content $(10 \%-12 \%)$. Further, elevated levels of glutelin and some of the essential amino acids such as lysine and threonine also indicated the qualitative improvement of grain protein of these lines. Based on higher GPC and protein yield in multilocational testing two high-yielding lines, viz. CR2829-PLN-37 (CR Dhan 310), and CR 2829-PLN-100 (CR Dhan 311/Mukul) in the genetic background of cv. Naveen with an average $10.2 \%$ and $10.1 \%$ GPC respectively, in polished rice were released at the national and state level respectively. These high-yielding varieties with high GPC can significantly contribute towards better nourishment of millions of underprivileged children depending mainly on rice for their nutrition.

Keywords: Backcross breeding, glutelins, NIR spectroscopy, rice.

RICE is the staple food for half of the world's population, contributing $29.1 \%$ protein for human consumption in the developing countries. Although grain protein content (GPC) of rice is lower than that of other cereals, rice protein is of higher quality because it contains essential amino acids such as lysine and has highest protein digestibility among the staple foods. Therefore, it is ideal to improve GPC in rice, which could help enhance nourishment of the rural poor who depend on it. It will also make a positive impact on the rapidly growing rice-based food and feed industry. The International Rice Research Insti-

*For correspondence. (e-mail: krishnenducrri@ gmail.com) tute (IRRI), Philippines evaluated 13,089 indica accessions; the protein content ranged from $4.3 \%$ to $18.2 \%$ (dry season) and $3.5 \%$ to $15.9 \%$ (wet season), which indicated wide genetic variability of this trait and thus the feasibility of developing high-protein rice cultivars ${ }^{1}$. Although it is difficult to combine high GPC with high yield in rice due to their negative correlation, such combinations have been achieved in many other cereals, including wheat and oats ${ }^{2}$. A major constraint to breeding rice for high GPC may be the low heritability of this trait, and it is affected by crop management practices such as application of nitrogen duration of crop growth, and degree of milling ${ }^{3}$. The recent identification of quantitative trait loci (QTLs) for GPC in rice has strengthened the contention that GPC has a genetic component and opened up the possibilities of marker-assisted selection of the trait ${ }^{4-6}$. The past few decades have seen intensive efforts to improve GPC of rice ${ }^{7,8}$, but high-yielding rice cultivars with high GPC remained elusive due to the absence of effective selection criteria for this complex trait and also because selection is expensive, laborious and timeconsuming.

Overcoming these constraints requires high-throughput screening for high GPC - a task that may facilitate identification of the most effective selection scheme. Nearinfrared (NIR) spectroscopy has been used in the present study, which has proved effective in predicting GPC and could be a reliable tool for high-throughput selection ${ }^{9}$. On the other hand, retrospection of the earlier rice breeding programme at IRRI for improvement of GPC revealed that pedigree and long-cycle recurrent selection could reduce the negative correlation between yield and protein content. However, the developed high-protein lines were not accepted in the long run probably either due to deviation in grain type and cooking qualities from the adapted parent, IR 8 , or due to low stability of their protein yield. Here we demonstrate how backcross breeding is useful for genetic improvement of GPC. Backcross method of selection is not only a reliable method to validate the additive effect of a QTL or a candidate gene, but also has proved useful for developing elite introgession lines. Backcross also helps reduce the effect of undesirable traits of agronomically inferior land race, used as donor. In addition, transferring favourable alleles from land races to crop plants with positive effects on qualityrelated traits has been proved feasible in several crops, including rice ${ }^{4,10}$. In this backcross breeding scheme we have used one such land race (ARC 10075) identified from the Assam Rice Collections of the National Rice Research Institute (NRRI) Rice GeneBank as a high GPC (11\%-13\%) donor ${ }^{11}$. We exercised three repeated backcrossings with recurrent parent, Naveen for developing backcross population. Two hundred and fifty $\mathrm{BC}_{3} \mathrm{~F}_{1}$ plants were selfed and the population was advanced by single-seed descent (SSD) method, which has been reported efficient not only with respect to time and cost of 
the breeding process, but also for producing a wide range of phenotypic variations with a high level of transgressive segregation ${ }^{12}$. The present breeding programme coupling backcrossing with SSD, delivered a large number of transgressive lines for GPC. We found more than $20 \%$ introgression lines for GPC showing substantial (data not presented) phenotypic similarities (plant architecture, maturity duration, etc.) with the recurrent parent, Naveen. However, the basic challenge of this breeding programme was to improve protein yield per unit area. It was demonstrated that both protein content and yield might be improved simultaneously up to a certain extent. It was reported that the higher expression of OsAAP6, a putative amino acid transporter, was correlated with higher GPC $^{13}$. Interestingly, OsAAP6 situated at the long arm of chromosome 1, controlled GPC with no effect on plant morphology and grain yield, suggesting that GPC could be improved without reduction in grain yield.

To evaluate yield, yield attributing traits and GPC, 159 $\mathrm{BC}_{3} \mathrm{~F}_{4}$ lines were planted along with the parents in kharif 2013. Significant variation was observed for plant yield (PY) per $\mathrm{m}^{2}$, GPC $(\%)$ and protein yield (PROY) $\left(\mathrm{g} / \mathrm{m}^{2}\right)$, and also all other yield-attributing traits (Supplementary Table 1). It was found that grain yield per square metre varied from 103.7 to $595.7 \mathrm{~g}$. Apparent GPC of these lines was estimated with $15 \mathrm{~g}$ dehusked grain using calibrated NIR spectroscopy developed in our laboratory ${ }^{14}$. The average GPC was $9.7 \%$ and range was $7.13 \%-$ $13.6 \%$. The estimated protein yield per square metre varied from 10.59 to $75.05 \mathrm{~g}$ with an average of $34.03 \mathrm{~g}$. Mean protein content in the population improved over Naveen. Although mean protein yield was lower than the protein yield of Naveen, $14 \%$ transgressive segregants for protein yield were observed over high-yielding parent. Calibrated NIR spectroscopy was also employed to estimate apparent amylose content of these lines ${ }^{14}$. Amylose content strongly influences the cooking characteristics of rice and other features related to grain quality. Amylose content and protein content in rice grains are reported to be negatively correlated ${ }^{15}$; as also observed in the present breeding programme $(r=-0.32)$. On the other hand, yield and protein content are generally negatively correlated. Therefore, selecting for high GPC may produce more genotypes with unacceptably low levels of amylose, or with low yielding ability in the rice grain. Simultaneous improvement of both the traits has been proved possible up to a certain extent. Through selection in $\mathrm{BC}_{3} \mathrm{~F}_{3}$ generation, we observed that negative correlation was significantly reduced $(r=-0.07)$ between PY and GPC in $\mathrm{BC}_{3} \mathrm{~F}_{4}$ generation. Based on PY, GPC, amylose content and PROY, the first two principal components explained $84 \%$ phenotypic variability among genotypes. PC1 was mainly constituted by the positive covariance coefficients of plant yield (0.68) and protein yield (0.71), and PC2 was mainly governed by the positive effects of amylose content (0.69) and grain yield (0.2). The 2D biplot derived from principal component analysis (PCA) helped identify desirable lines and reduced the possible risk of choosing extreme points (genotypes) which might be unstable for GPC or protein yield (Figure 1). Introgression lines in Naveen background with the combination of high GPC, grain yield, protein yield and desirable amylose content were PLN-15 (11.73\%, $563.9 \mathrm{~g}, \quad 66.15 \mathrm{~g}$, $23.08 \%$ ), PLN-37 (10.76\%, 590.2 g, $63.51 \mathrm{~g}, 23.16 \%)$, PLN-100 (10.33\%, $595.71 \mathrm{~g}, 61.54 \mathrm{~g}, 23.03 \%)$ and PLN$191(10.83 \%, 560 \mathrm{~g}, 60.65 \mathrm{~g}, 22.18 \%)$. They have comparable maturity duration (121-127 days) and plant height $(108-115 \mathrm{~cm})$ with Naveen $(124$ days and $113 \mathrm{~cm}$ respectively). Seven high-yielding introgression lines $\left(\mathrm{BC}_{3} \mathrm{~F}_{5}\right)$ were selected with high GPC and phenotypic resemblance with Naveen. The selected seven lines were grown at the experimental plot of the NRRI, Cuttack in 2014 and kharif 2014. Nitrogen, phosphorus and potassium were supplied at 80,60 and $40 \mathrm{~kg} / \mathrm{ha}$ respectively, in kharif and 120, 60 and $60 \mathrm{~kg} / \mathrm{ha}$ respectively, in rabi. Phosphorus (as single super phosphate) was applied as a basal dose, and nitrogen (as urea) and potassium (as muriate of potash) were applied in two equal doses at 30 days after transplanting and at 50\% flowering. GPC was estimated in polished rice by the standard micro-Kjeldahl method ${ }^{16}$. Single grain protein content (SGPC) was also estimated (from the average of 10 grains), which was observed to be a more stable parameter than GPC with higher percentage of heritability than the latter. All lines had significantly higher GPC, SGPC and protein yield than their high-yielding parent (Table 1). They also had acceptable grain and cooking quality (Supplementary Table 2). It has been reported earlier that improvement of grain protein content reduced the protein quality and resulted in hardening of the cooked rice due to increase of prolamin fraction. Therefore, quality of protein must be assessed in high-yielding elite lines. Hence, grain proteins of selected lines were fractionated into albumins, globulins, prolamins and glutelins. Extraction of rice proteins was performed following standard procedure ${ }^{17}$. The extracted proteins were freeze-dried and stored at $-70^{\circ} \mathrm{C}$. The protein content of each fraction was measured ${ }^{18}$. Significant variation was observed among all genotypes for the four fractions. The mean contents of albumin, globulin, glutelin and prolamin fractions of these genotypes in polished rice were $0.802 \%, 1.282 \%, 11.257 \%$ and $0.319 \%$ respectively (Table 2). Contents of albumin, globulin, glutelinand prolamin among the genotypes ranged from $0.283 \%$ to $1.48 \%, 0.90 \%$ to $1.575 \%, 8.889 \%$ to $13.515 \%$ and $0.24 \%$ to $0.443 \%$ respectively. Except one, all highprotein lines had significantly higher glutelin content than Naveen. Glutelin contains essential amino acids such as lysine and is the major constituent of protein body II in the endosperm which is more digestible than protein body I, that contains mostly prolamin. Therefore, higher accumulation of glutelin ensured better protein quality in most of these lines. The ratio of prolamin to glutelin fractions 


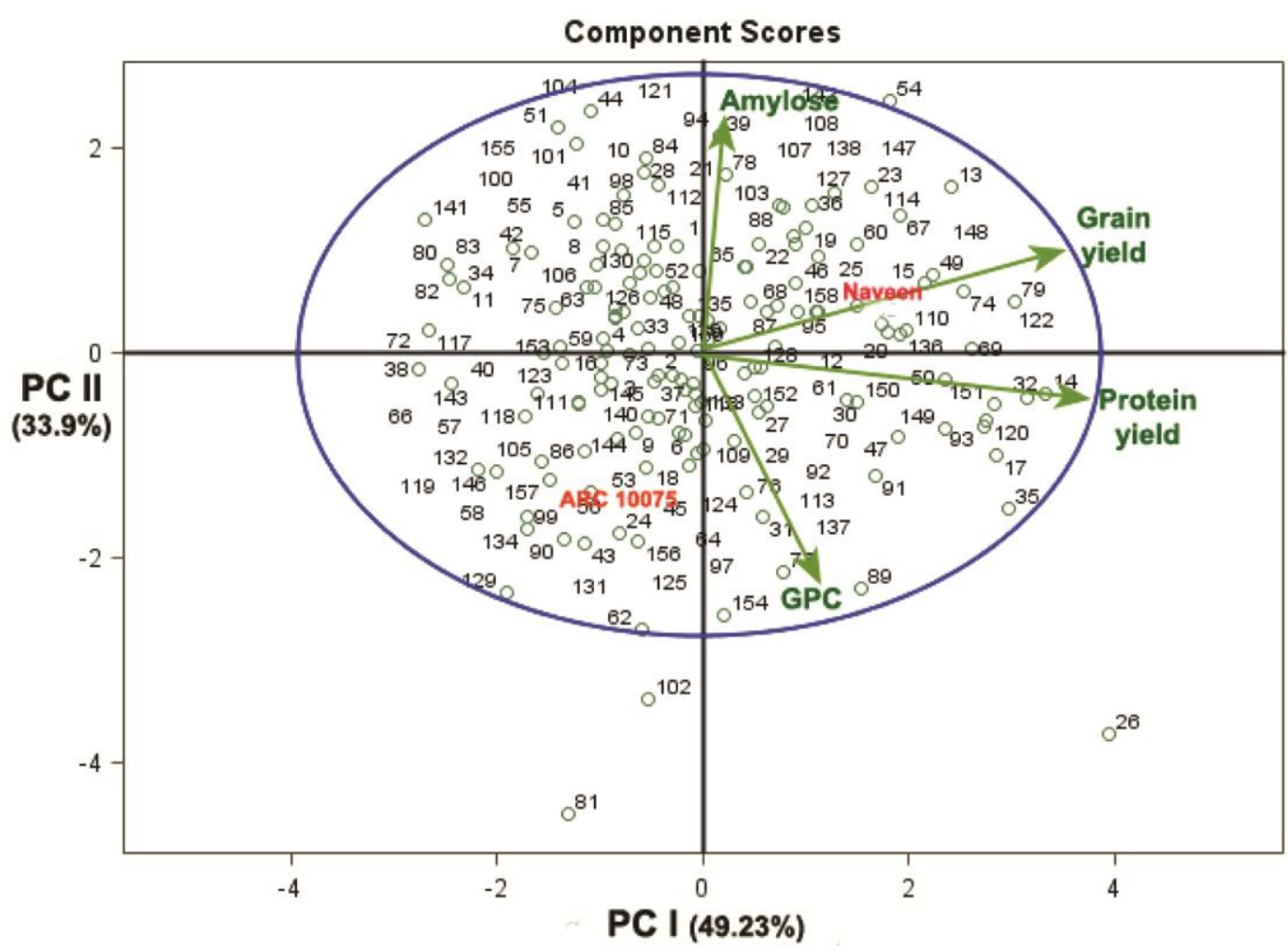

Figure 1. Two-dimensional biplot derived from principal component analysis of backcross-derived population $\left(\mathrm{BC}_{3} \mathrm{~F}_{4}\right)$ from Naveen and ARC 10075.

Table 1. Evaluation of selected high-yielding introgression lines $\left(\mathrm{BC}_{3} \mathrm{~F}_{4}\right)$ in Naveen background for grain protein content (GPC), single grain protein content (SGPC), grain yield and protein yield

\begin{tabular}{|c|c|c|c|c|c|c|c|c|c|c|}
\hline & \multirow[b]{2}{*}{ Parameters } & \multirow{2}{*}{$\begin{array}{l}\text { High GPC } \\
\text { donor } \\
\text { ARC } 10075\end{array}$} & \multirow{2}{*}{$\begin{array}{l}\text { Check-1 } \\
\text { Naveen }\end{array}$} & \multicolumn{7}{|c|}{ Introgression lines in Naveen background } \\
\hline & & & & PLN-100 & PLN-109 & PLN-31 & PLN-32 & PLN-37 & PLN-36 & PLN-97 \\
\hline \multicolumn{11}{|l|}{ Trait (season-wise) } \\
\hline \multirow[t]{2}{*}{ Rabi 2014} & GPC (\%) & 10.80 & 7.74 & 10.40 & 11.17 & 12.10 & 11.90 & 10.51 & 10.15 & 9.86 \\
\hline & SGPC (mg) & 2.40 & 1.56 & 1.98 & 1.68 & 2.15 & 1.85 & 1.93 & 1.99 & 1.94 \\
\hline Kharif 2014 & GPC $(\%)$ & 10.88 & 8.13 & 9.47 & 10.43 & 9.72 & 9.47 & 9.79 & 10.45 & 10.25 \\
\hline \multirow[t]{2}{*}{ Mean } & GPC $(\%)$ & 10.84 & 7.93 & 9.93 & 10.80 & 10.91 & 10.68 & 10.15 & 10.30 & 10.06 \\
\hline & $\mathrm{SGPC}(\mathrm{mg})$ & 2.49 & 1.58 & 2.04 & 1.91 & 2.16 & 1.93 & 2.00 & 2.04 & 2.04 \\
\hline \multirow{2}{*}{$\begin{array}{l}\% \text { Improvement of protein } \\
\text { content over check }\end{array}$} & GPC $(\%)$ & 28.61 & & 21.17 & 28.19 & 25.87 & 28.66 & 24.45 & 25.25 & 24.27 \\
\hline & SGPC (\%) & 35.91 & & 24.63 & 21.40 & 27.48 & 23.83 & 25.02 & 23.58 & 25.71 \\
\hline Mean grain yield (kg/ha) & & 2450.00 & 4060.00 & 3890.00 & 3870.00 & 3900.00 & 4310.00 & 4246.00 & 3990.00 & 3880.00 \\
\hline $\begin{array}{l}\text { \% Improvement of grain } \\
\text { yield over check (Naveen) }\end{array}$ & & & & -4.19 & -4.68 & -3.94 & 6.16 & 4.58 & -1.72 & -4.43 \\
\hline
\end{tabular}

ranged from 0.022 to 0.037 . Most of the high-protein lines had similar or slightly lower values in prolamin/ glutelin ratio than the adapted parent, Naveen which ensured maintaining the cooking quality of these introgression lines. Finally, amino acid composition is also a key factor determining the nutritional quality of cereal grains ${ }^{19}$. We hydrolysed polished grain sample with $6 \mathrm{~N}$ hydrochloric acid at $110^{\circ} \mathrm{C}$ under anaerobic condition for $24 \mathrm{~h}$ and neutralized with $6 \mathrm{~N} \mathrm{NaOH}$; the derivatized samples were injected in HPLC for identification and qualification of amino acids using standard procedure ${ }^{20}$. Most of the high-protein lines had significantly higher levels of lysine, threonine, leucine, isoleucine, valine, phenylalanine, alanine, proline, glutamic acid, arginine 


\section{RESEARCH COMMUNICATIONS}

Table 2. Fraction of soluble proteins (percentage in $100 \mathrm{~g}$ polished rice sample) in introgression lines for GPC in Naveen background and their parents

\begin{tabular}{|c|c|c|c|c|c|c|}
\hline Genotype & Albumin $(\%)$ & Globulin $(\%)$ & Prolamin $(\%)$ & Glutelin (\%) & Prolamin/glutelin ratio & Total \\
\hline ARC 10075 & 0.434 & 1.415 & 0.443 & 12.864 & 0.034 & 15.156 \\
\hline PLN-37 & 0.44 & 1.263 & 0.352 & 13.519 & 0.026 & 15.575 \\
\hline PLN-100 & 0.565 & 1.292 & 0.356 & 12.49 & 0.029 & 14.703 \\
\hline PLN-32 & 0.988 & 1.283 & 0.24 & 11.058 & 0.022 & 13.57 \\
\hline PLN-109 & 0.283 & 0.9 & 0.242 & 11 & 0.022 & 12.425 \\
\hline PLN-31 & 0.823 & 1.507 & 0.365 & 11.61 & 0.031 & 14.306 \\
\hline Mean & 0.802 & 1.282 & 0.319 & 11.257 & 0.028 & 13.660 \\
\hline CD (5\% level) & 0.06 & 0.11 & 0.08 & 0.35 & - & 0.41 \\
\hline
\end{tabular}

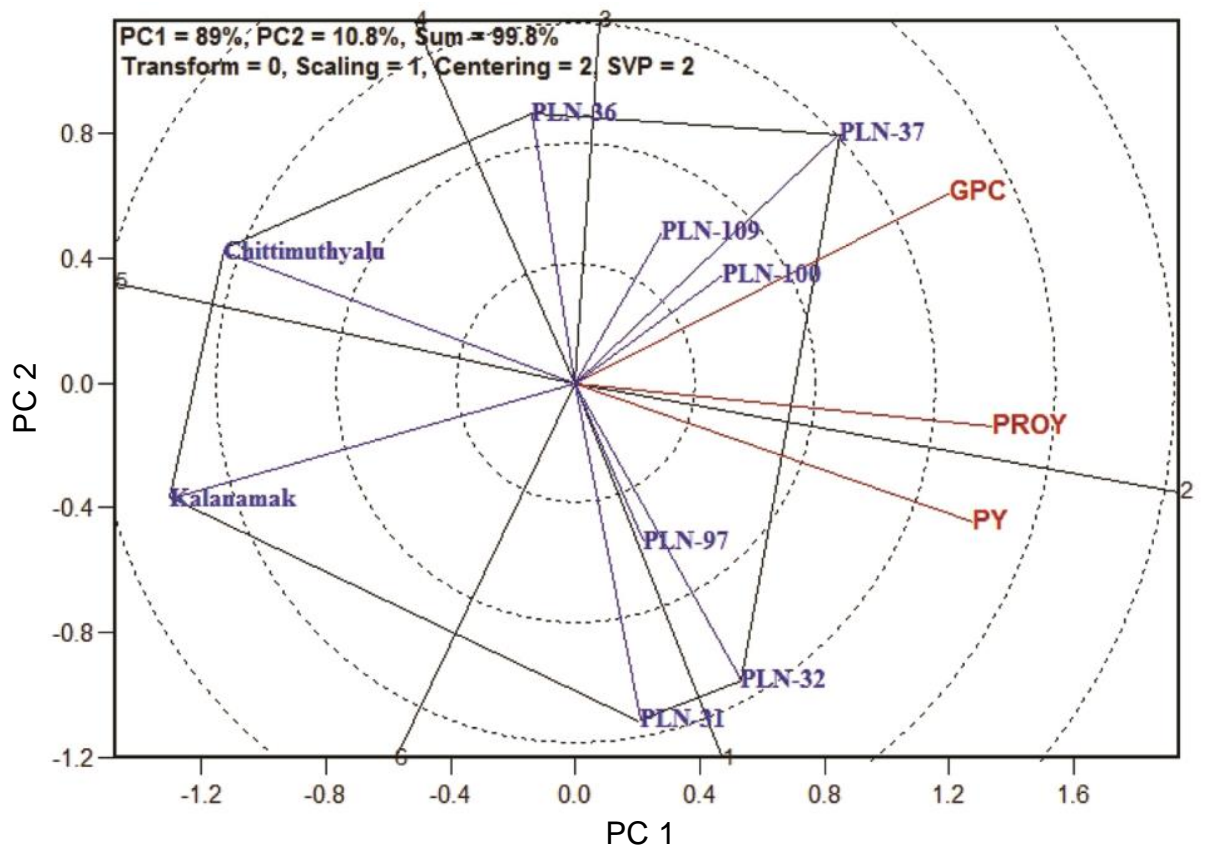

Figure 2. 'Which-won-where' biplot view of selected high protein lines in multilocational (10 locations) testing for grain protein content (GPC), plant yield (PY) and protein yield (PROY).

and total amino acid compared to recurrent high-yielding parent (Supplementary Table 3). Elevated levels of some of the essential amino acids in the derived lines showed improved quality of storage protein. This qualitative improvement has been earlier largely restricted to maize crop through enrichment of grain lysine in the form of QPM lines and has now been extended to rice, which is a major crop of India ${ }^{19}$.

These superior cultures were nominated for multilocational testing (AICRIP biofortification trial in 2014). Data on GPC, grain yield $(\mathrm{kg} / \mathrm{ha})$ and protein yield (kg/ha) over the 10 locations of these lines along with checks, Kalanamak and Chittimithyalu were analysed and GGE biplot symmetric view was used to explain the 'which-won-where' patterns for genotypes and environ- ments. Figure 2 displays the 'which-won-where' patterns of genotypes in multi-environmental trials. In this biplot, a polygon was formed by connecting the vertex genotypes with straight lines and the rest of the genotypes were placed within the polygon. The polygon view of a biplot is generally considered as the best way to visualize the interaction patterns between genotypes and environments $^{21}$. The vertex genotypes in this polygon were PLN-37, PLN-36, PLN-31, PLN-32, Kalanamak and Chittimuthyalu. Two main principal components (PC I and PC II) jointly explained $99.8 \%$ of the variation which was constituted by effects of PY, GPC and protein yield. These traits revealed the genotypes with high performance located in the vertex of the polygon derived through $\mathrm{G} \times \mathrm{GE}$ interaction. The genotypes located at the 
middle of the polygon were average performers for all these traits. In the sector where both PROY and GPC were located, as vertex genotype, PLN-37 was the best performer for these traits. Similarly, based on the vertex position, PLN-32 was the best performer for PY. Genotypes and 10 testing environments were placed in the Biplot derived from analysis of protein yield. PC I and PC II jointly explained $74 \%$ of the variation. PLN-37 and PLN100 were located closer to West Bengal, Odisha and Uttar Pradesh in the biplot (Supplementary Figure 1). Among these lines, PLN-37 had $10.2 \%$ average protein content in polished grain which was $21.6 \%$ and $12.44 \%$ higher than quality checks Kalanamak and Chittimuthyalu respectively, in trials conducted at the 10 locations (Supplementary Table 4). Performance in grain yield was also good in all the zones, with an average $4483 \mathrm{~kg} / \mathrm{ha}$. It outperformed yield check, Samba Mahsuri by registering yield superiority of $6.81 \%$. It has a long panicle with medium slender grain. This high-yielding variety (CR 2829-PLN-37) with high GPC has been released by the Central Variety Release Committee in 2016 for Odisha, Uttar Pradesh and Madhya Pradesh as CR Dhan 310 (ref. 22). Another line PLN-100 (CR 2829-PLN-100) has been released by State variety Release Committee of Odisha as Mukul (CR Dhan 311) for high protein content $(10.1 \%)$ and moderately high $\mathrm{Zn}$ content $(20 \mathrm{ppm})$, with grain yield of $4330 \mathrm{~kg} / \mathrm{ha}$. These varieties were found better or at par with the checks with regard to their response to important biotic stresses. They are medium early (122-125 days) with semi-dwarf $(108-115 \mathrm{~cm})$, compact plant type and have good initial growth and tillering ability. The protein yield per unit area of CR Dhan 310 and CR Dhan 311 was 457 and $438 \mathrm{~kg} / \mathrm{ha}$ compared to Naveen $(367 \mathrm{~kg} / \mathrm{ha})$ and its high GPC donor ARC10075 (305 kg/ha) (Supplementary Table 4). In agronomic trials at the NRRI farm during kharif 2014, these two varieties also performed at par with the high-yielding parent, Naveen. They had high head rice recovery $(>60 \%)$, and good grain and cooking qualities such as intermediate amylose content $(22 \%-$ 24\%) (Supplementary Table 2). They have been well accepted by the farmers due to their resemblance for grain and plant type with the recurrent parent, Naveen, a popular rice variety of eastern India. Genotypic similarity of these varieties with Naveen was also established by employing more than 400 SSR primers distributed in all 12 chromosomes. Sixty-eight primers, including some markers linked with reported QTLs were found polymorphic between Naveen and ARC 10075. Fingerprinting pattern revealed that these two high-protein rice varieties were around $95 \%$ genetically similar with Naveen (Supplementary Figure 2). Both these introgressed lines carried a genomic region from ARC 10075 of the marker RM 11 in chromosome 7, which was reported to be associated with QTL pro 7 for GPC $^{23}$. PLN-100 also contained a genomic region from ARC 10075 for the marker RM 167, which was reported to be associated with the
QTL pro11 for GPC on chromosome 11 (ref. 4). Another variety, PLN-37 contained a genomic region from high protein donor for the marker RM232, which was associated with QTL pro2 for GPC on chromosome 2 (refs 4, 5). We have also identified a QTL for GPC (qGPC1.1) on chromosome 1 through SNP genotyping using a 40894 SNP chip, which has been found stable over the environments and associated with the locus, Os01g0111900 on chromosome 1, encoding a glutelin family protein ${ }^{24}$. These two high-protein varieties also contained this QTL. The present work reports a significant improvement in GPC coupled with a background of high yields, which when combined with validation of QTLs for GPC, would certainly help to ensure future research and development - a step towards better nutrition of underprivileged populations of the Asia-Pacific region.

1. Juliano, B. O., Ignacio, C. C., Panganiban, V. M. and Perez, C. M., Screening for high protein rice varieties. Cereal Sci. Today, 1968, 13, 299

2. Vasal, S. K., The role of high lysine cereals in animal and human nutrition in Asia. In Protein Sources for the Animal Feed Industry, Food and Agriculture Organization of the United Nations, Rome, Italy, 2002, pp. 97-108.

3. Perez, C. M., Juliano, B. O., Liboon, S. P., Alcantara, J. M. and Cassman, K. G., Effects of late nitrogen fertilization application on head rice yield, protein content, and grain quality of rice. Cereal Chem., 1996, 73, 556-560.

4. Aluko, G., Martinez, C., Tohme, J., Castano, C., Bergman, C. and Oard, J. H., QTL mapping of grain quality traits from the interspecific cross Oryza sativa $\times$ O. glaberrima. Theor. Appl. Genet., 2004, 109, 630-639.

5. Yu, Y. H., Li, G., Fan, Y.-Y., Zhan, K. Q., Min, J., Zhu, Z. W. and Zhuang, J. Y., Genetic relationship between grain yield and the contents of protein and fat in a recombinant inbred population of rice. J. Cereal Sci., 2009, 50, 121-125.

6. Ye, G., Liang, S. and Wan, J., QTL mapping of protein content in rice using single chromosome segment substation lines. Theor. Appl. Genet., 2010, 121, 741-750.

7. Khush, G. S. and Juliano, B. O., Status of rice varietal improvement for protein content at IRRI. In Nuclear Techniques for Cereal Grain Protein Improvement, Proceedings of Research Coordination Meeting, International Atomic Energy Agency, Vienna, Austria, 1984, pp. 199-202.

8. Mahmoud, A. A., Sukumar, S. and Krishnan, H. B., Interspecific rice hybrid of Oryza sativa $\times$ Oryza nivara reveals a significant increase in seed protein content. J. Agric. Food Chem., 2008, 52, $476-482$.

9. Xie, L. H. et al., Optimisation of near-infrared reflectance model in measuring protein and amylose content of rice flour. Food Chem., 2014, 142, 92-100.

10. Septiningsih, E. M., Trijatmiko, K. R., Moeljopawiro, S. and McCook, S. R., Identification of quantitative trait loci for grain quality in an advanced backcross population derived from the Oryza sativa variety IR 64 and the wild relative $O$. rufipogon. Theor. Appl. Genet., 2003, 107, 1433-1441.

11. Chattopadhyay, K., Das, A. and Das, S. P., Grain protein content and genetic diversity of rice in north eastern India. Oryza, 2011, 48, 73-75.

12. Moon, H. P., Kang, K. H., Choi, I. S., Jeong, O. Y., Hong, S. C., Choi, S. H. and Choi, H. C., Comparing agronomic performance of breeding populations derived from anther culture and single seed descent in rice. In Advances in Rice Genetics (eds Khush, G. 
S., Brar, D. S. and Hardy, B.), International Rice Research Institute (IRRI), USA, 2003, pp. 3-5.

13. Peng, B. et al., OsAAP6 functions as an important regulator of grain protein content and nutritional quality in rice. Nature Commun., 2014, 5, 4847; doi:10.1038/ncomms5847.

14. Bagchi, T. B., Sharma, S. G. and Chattopadhyay, K., Development of NIRS models to predict protein and amylose content of brown rice and proximate compositions of rice bran. Food Chem., 2015, 191, 21-27; doi:org/10.1016/j.foodchem.2015.05.038.

15. Yang, L. J., Xu, L. and Li, J. Y., Analysis of correlation between protein content, amylose content in the unpolished rice and 1000grain weight in six different varieties' rice. J. Shanghai Normal Univ. (Nat. Sci.), 2004, 10 (Suppl.), 55-58.

16. Yoshida, S., Forno, D. A., Cock, J. H. and Gomez, K. A., Laboratory Manual for Physiological Studies of Rice, IRRI, Manila, Philippines, 1976, 3rd edn, pp. 1-83.

17. Ju, Z., Hettiarachchy, N. and Rath, N., Extraction, denaturation and hydrophobic properties of rice flour proteins. J. Food Sci., 2001, 66, 229-232.

18. Lowry, O. H., Rosebrough, N. J., Lewis Farr, A. and Randall, R J., Protein measurement with the Folin phenol reagent. J. Biol. Chem., 1951, 193, 265

19. Ufaz, S. and Galili, G., Improving the content of essential amino acids in crop plants: goals and opportunities. Plant Physiol., 2008, 147, 954-961.

20. Pal, P. et al., Effect of nonthermal plasma on physico-chemical, amino acid composition, pasting and protein characteristics of short and long grain rice flour. Food Res. Int., 2016, 81, 50-57.

21. Yan, W. and Kang, M. S., GGE Biplot Analysis: A Graphical Tool for Breeders, Geneticists, and Agronomists, CRC Press, Boca Raton, FL, USA, 2003.

22. DARE Annual Report 2015-2016, Indian Council of Agricultural Research, New Delhi, 2016

23. Guo, Y., Mu, P., Liu, J., Lu, Y. and Li, Z., QTL mapping and $\mathrm{Q} \times \mathrm{E}$ interaction of grain cooking and nutrient qualities in rice under upland and lowland environments. J. Genet. Genomics, 2007, 34(5), 420-428

24. Chattopadhyay, K. et al., Detection of stable QTLs for grain protein content in rice (Oryza sativa L.) employing high throughput phenotyping and genotyping platforms. Sci. Rep., 2019, 9, 3196; doi.org/10.1038/s41598-019-39863-2.

ACKNOWLEDGEMENT. We thank the research guidance received from Dr T. Mohapatra, Director General, ICAR and also thank the Director, ICAR-NRRI, Cuttack and the Coordinator of CRP on Biofortification project, ICAR for research funding.

Received 28 May 2017; accepted 6 August 2019

doi: $10.18520 / \mathrm{cs} / \mathrm{v} 117 / \mathrm{i} 10 / 1722-1727$

\section{Utilization of mahua resources: traditional knowledge as a tool for sustainable management}

\author{
H. T. Hegde*, R. P. Gunaga, N. S. Thakur, \\ J. B. Bhusara and R. L. Soundarva \\ College of Forestry, Navsari Agricultural University, \\ Navsari 396 450, India
}

Mahua (Madhuca longifolia var. latifolia Roxb. A. Chev.) tree has religious and aesthetic value in the ethos of many tribes of Gujarat, India. Traditional knowledge of the people about the various uses of mahua is shrinking rapidly due to the change in socioeconomic status. The present study was conducted to draw the utilization pattern of mahua resources and to document the traditional knowledge of the people involved in its usage in Gujarat. Information regarding pattern of utilization and traditional knowledge about mahua was collected using the participatory rural appraisal method. Results highlighted interesting information on traditional knowledge about processing, product development and medicinal value of mahua resources. The species is under threat and receives less care compared to the benefits drawn from it. Therefore, sustainable management of this valuable species is needed by taking a lesson from traditional knowledge.

Keywords: Mahua resources, sustainable management, traditional knowledge, utilization pattern.

MADHUCA longifolia var. latifolia (Mahua) tree has religious and aesthetic value in the ethos of many tribes of Gujarat, India. Since long they have been using mahua resources for food, fermented products, medicine, etc. ${ }^{1-3}$. In the tribal areas of Gujarat, people regularly use mahua seed oil for cooking and for lightening lamps. Mahua flowers are used in various by-products ${ }^{4}$. The estimated production of mahua flowers is more than one million tonnes in the country ${ }^{1}$. Similarly, the annual production of mahua seeds is around 1,085,300 quintals per year, and the prices vary from Rs 1000 to 1500 per quintal ${ }^{5}$. According to a recent report ${ }^{6}$, the total quantity of mahua flowers collected in Gujarat during 2016-17 was 4265 quintals and worth Rs 184.95 lakhs. The total quantity of seeds collected during the same period was 2212.59 quintals and worth of Rs 99.5 lakhs. This clearly shows the dependency of local people on the mahua tree. Populations of mahua are being traditionally protected by local communities, but due to anthropogenic pressure many of mahua population became disturbed sites ${ }^{7}$. Mahua plays an important role in the day-to-day life of tribal people who utilize different parts of this species in various ways.

*For correspondence. (e-mail: hegdeht@gmail.com) 